\title{
Artigos
}

\section{A palavra do outro na redação-Enem: Polifonia ou Sobreposição de discursos? ${ }^{1}$}

A word from the other in Enem-writing: Polyphony or Overlap of speeches?

Hélder Sousa Santos*

\begin{abstract}
RESUMO: No presente trabalho, buscamos compreender como a palavra do outro foi agenciada por um scriptor em uma redação caracterizada de "Nota 1000" pela instância corretora de vestibular ENEM - Exame Nacional do Ensino Médio (2011) —, ao (re)tomar enunciados constituídos sócio historicamente acerca do tema "Viver em rede no século XXI: os limites entre o público e o privado". Dito de outro modo, vamos descrever e interpretar, pautados em pressupostos teóricos de Bakhtin (1981; 1988a e 1988b; 1997), mo(vi)mentos de tomada de posição desse scriptor (no nível de sua argumentação) ante à palavra do outro. Tais mo(vi)mentos permitir-nos-ão indicar se se tratam de (e)feitos de polifonia discursiva (consoante ao pensamento bakhtiniano) ou de sobreposição de discursos. Dessa feita, sernos-á possível corroborar a (in)verdade escutada e propalada na/pela máxima "todo discurso é polifônico".
\end{abstract}

PALAVRAS-CHAVE: Dialogismo. Discurso. Polifonia. Sobreposição discursiva. Redação-ENEM.

\begin{abstract}
In this work, we aim at studying how other`s word was brokered by a scriptor in a writing featured as "maximum score" by the broker instance of ENEM National High School Exam (2011) - when (re)making social statements made historically on the theme "Living networked in the XXI century: the boundaries between public and private". In other words, we describe and interpret, guided by Bakhtin's theoretical framework (1981; 1988a and 1988b; 1997), mo(ve)ments that have been adopted by this scriptor (at the level of its argumentation) before the word of the other. Such mo(ve)ments will allow us to indicate marks of discursive polyphony (according to Bakhtinian thoughts) or overlapping discourses. This will make possible to corroborate the (un)truth that is heard and diffused by the maxim "all discourse is polyphonic."
\end{abstract}

KEYWORDS: Dialogism. Speech. Polyphony. Discursive overlap. Writing Vestibular-ENEM.

\footnotetext{
${ }^{1}$ Este texto é resultado de meu trabalho de qualificação em Área Complementar (A.C.), desenvolvido conforme práticas acadêmicas do Programa de Pós-graduação em Estudos Linguísticos (PPGEL) da Universidade Federal de Uberlândia (UFU) — curso de doutorado. Agradeço ao prof. Dr. João Bosco Cabral dos Santos (meu orientador), às professoras Dra. Carla Nunes Vieira Tavares e Dra. Cristiane Carvalho de Paula Brito a leitura atenciosa de nossas (re)formulações e a participação conjunta em mo(vi)mentos de escrita, sem as quais pouco do exposto a seguir teria se constituído.

* Doutorando em Estudos Linguísticos pela Universidade Federal de Uberlândia (UFU). Professor de Língua Portuguesa, Literatura e Redação do Instituto Federal Minas Gerais (IFMG).
} 
Todas as palavras (enunciados, produções de discurso literárias), além das minhas próprias, são palavras do outro. Eu vivo num mundo de palavras do outro. E toda a minha vida é uma orientação neste mundo; é reação às palavras do outro (uma reação infinitamente diversificada) a começar pela assimilação deles (no processo de domínio inicial do discurso) $e$ terminando na assimilação das riquezas da cultura humana.

Bakhtin (1997, p. 379).

\section{Considerações iniciais}

Ao falar da presença da palavra do outro ${ }^{2}$ na redação-ENEM ${ }^{3}$ (BRASIL, 2012), ou seja, o dialogismo, colocamos em destaque uma das proposições centrais formuladas pelo filósofo russo Mikhail Bakhtin (1895-1975) em “Problemas da Poética de Dostoiévski” (2013 [1981]) — doravante, PPD —, obra que discute e analisa uma série de questões voltadas para a filosofia da linguagem, de modo geral, e para a linguagem literária. Na ocasião, um escrutínio de elaborações teóricas do autor permitir-nos-á fundamentar nossa compreensão, ancorada sobremodo no questionamento do estatuto (a ser) conferido ao outro no ato singular redacional de (re)dizê-lo. Trata-se de um efeito polifônico, dentro dos moldes bakhtinianos, ou de uma sobreposição discursiva, um efeito heterogêneo constitutivo da própria linguagem? questionamo-nos.

Antes, cabe-nos produzir uma releitura atenta de teses nodais aos estudos de Bakhtin e de seu Círculo ${ }^{4}$, (re)pensando, em seguida, fundamentos singulares à sua visão dialógica de linguagem. Noutras palavras, é mister a retomada de noções, conceitos e teorias bakhtinianos para propormos um exame acurado da presença da palavra do outro na redação-ENEM. Tais elaborações do autor, a saber, a "heterogeneidade da palavra”5, o “dialogismo” e a “exotopia”,

\footnotetext{
${ }^{2}$ Esse outro - social, histórico, ideológico e psíquico — é discurso e interlocutor, e não o ser (alguém) no mundo. Ele é parte da configuração do diálogo na linguagem.

${ }^{3}$ No Brasil, o ENEM (Exame Nacional do Ensino Médio) constitui-se de uma prova de seleção de candidatos (estudantes) a vagas em Universidades públicas.

4 Trata-se de um grupo de estudiosos, que, nas primeiras décadas do século XX (1919-1929), discutiu e problematizou a tese bakhtiniana da interação na linguagem (seus alcances teórico-metodológicos prováveis à demonstração de uma realidade plausível de língua, o fundamento de sua existência: o homem $e$ a sociedade).

${ }^{5}$ Esse conceito, problematizado por diferentes áreas da linguística, não resulta de uma construção autoral de Bakhtin. Trata-se, na verdade, de um princípio teórico axiomático assumido por linguistas atuais para validar a tese da dialogicidade da linguagem como princípio gerador de discursos. "Atribuímo-lo”, no entanto, a Bakhtin — à ideia de heteroglossia ou plurilinguismo dialogizado enfocada(o) pelo autor, isto é, o entrecruzamento multiforme de vozes sociais em textos — apenas como forma de traçar um percurso argumentativo nosso, qual
} 
respectivamente, conduzir-nos-ão ao entendimento de questões da "teoria”6 polifônica exposta e consagrada em PPD. Esta, conforme ainda veremos, possui particularidades teóricometodológicas perante o sistema conceitual construído por Bakhtin para investigar o tema “vozes” no/do discurso literário.

Neste passo, deixamos explícitas as diretrizes metodológicas da problematização bancada pelo presente estudo ao se perguntar, de saída, sobre o lugar da palavra do outrem no fio do dizer, seu papel bancado - assumido e trabalhado - em um contexto específico: a redação-ENEM. Ora, uma questão daí entrevista é cara às nossas discussões: indagamos sobre o fato de que nem todo discurso seja polifônico — dentro da óptica bakhtiniana. Isto porque em Bakhtin (2013) há requisitos singulares envolvendo o conceito de polifonia; esses precisarão ser relidos cuidadosamente por nós a fim de evitar seu fetichismo, e, consequentemente, barrar a multiplicação de vulgadas prováveis (já) em circulação. O ato de nos volver a critérios formulados pelo autor ao tratar das várias vozes que constituem um discurso dar-nos-á, por conseguinte, acesso às relações que estão em causa aí.

Em vista do posicionamento exposto no parágrafo precedente, elaboramos uma hipótese de trabalho, qual seja: a despeito de haver, entre estudiosos de linguagem, apropriações “consensuais” de enunciados tais como “a consciência é polifônica” ou "todo discurso é polifônico”, indicamos aí a necessidade de revisão de sentidos, buscando, para tal, confrontar à explicação metalinguística “várias vozes = polifonia?” o seu avesso, a monofonia ou “sobreposição discursiva”; reiterados, no último caso, termos de Faraco (1988). Para tanto, fazse pertinente a produção de leituras do arcabouço teórico bakhtiniano aludido, já que essa feita (nossa) obriga a posição leitor — também ocupada da revisita a pressupostos fundantes à categoria de polifonia no/do discurso — tecer conclusões.

Na sequência, aos poucos, colocamo-nos a perfilar os propósitos traçados acima. Primeiramente, falaremos do conceito de "heterogeneidade da palavra”, procurando ressaltar dali questões que nos permitam notar o fenômeno linguagem de uma forma-outra: não apenas pelo viés linguístico (verbal), mas também pelo caráter social-ideológico (extraverbal) que o constitui. Feito isso, procederemos à leitura da noção bakhtiniana de “dialogismo”, que decerto conscientizar-nos-á sobre quais fatos implicam a construção do conceito de polifonia (também

seja: partir da ideia de heterogeneidade discursiva, uma propriedade da linguagem, para tratar, na sequência, de dois conceitos importantes à empreitada bakhtiniana: dialogismo-polifonia e exotopia.

${ }^{6}$ Faraco (2008) questiona se seria, de fato, uma teoria as caracterizações e explicações construídas para o termo polifonia em PPD (2013). Por isso, optamos (no curso de nosso texto) por manter o termo entre aspas. 
de Bakhtin). Em resumo, não podemos perder de vista que os pressupostos "heterogeneidade da palavra” e “dialogismo” são determinantes à introdução de questões novas aos estudos linguísticos; aquele, uma propriedade geral de existência do discurso, é (re)pensado bakhtinianamente pelo diálogo heurístico instituído e estruturado por este.

Abaixo, vejamos, então, especificidades desses conceitos, hoje, em voga em áreas diferentes de conhecimento.

\section{Sobre o conceito de heterogeneidade da palavra}

Bahktin (1988a), em sua obra célebre "Marxismo e Filosofia da linguagem”, interpelando-se acerca do que seja a linguagem, a palavra do outro, desfere críticas às duas formas de pensamento lógico-linguístico que domina(ra)m os estudos de linguagem por anos: o subjetivismo idealista e o objetivismo abstrato. Isto porque - a despeito de compreensões até então arroladas em torno do objeto língua - a palavra não se reduz a categorias preestabelecidas em determinado campo cognitivo e explicável, a propósito, em termos psicológicos ou sociológicos. Há, ao contrário, outros fatores ${ }^{7}$, sociais e históricos, a princípio exteriores à sua natureza, afetando, assim, o (per)curso de significação do qual fazem parte e não poderá ser de outro jeito - sentidos e sujeitos, sempre heterogêneos, decentrados em relação a si e em relação a uma origem apenas imaginária.

Examinando, com efeito, as posições defendidas pela primeira tendência - o subjetivismo idealista - , Bakhtin (idem, p. 75- 76) sumariza-as em quatro proposições, a saber:

1. A língua é uma atividade, um processo criativo ininterrupto de construção (“energia”), que se materializa sob a forma de atos individuais de fala. 2. As leis da criação linguística são essencialmente as leis da psicologia individual. 3. A criação linguística é uma criação significativa análoga à criação artística. 4. A língua, enquanto produto acabado (“ergon”), enquanto sistema estável (léxico, gramática, fonética), apresenta-se como um depósito inerte, tal como a lava fria da criação linguística, abstratamente construída pelos linguistas com vistas à sua aquisição prática como instrumento pronto para ser usado.

\footnotetext{
7 Aqui, como forma elucidativa, lembramos que os trabalhos dos linguistas Austin (1962) e Benveniste (1966, 1974), respectivamente, são os primeiros a notar esse efeito de a-mais (outros fatores) constitutivo(s) da linguagem. Austin, em sua obra "Quando dizer é fazer” (idem), observa que no próprio ato de/do dizer há o engajamento do falante; este, conforme ressaltam várias problematizações do autor, está, então, marcado ali — na/pela (sua) prática concreta de linguagem. Já Benveniste (idem) fala-nos sobre o estatuto da relação eu-outro (actantes do discurso) como princípio de subjetividade na língua e na linguagem; o sujeito e a enunciação, poderíamos assim resumir, são igualmente importantes aos estudos linguísticos, pondera o autor.
} 
Vejamos, a partir da citação em tela, que as explicações forjadas pela orientação subjetivista idealista — para caracterizar a natureza pressuposta ao objeto língua — são puramente psicológicas, enfatizando, a rigor, a ação e a criatividade do indivíduo frente às formas linguísticas. Em tese, tal qual pondera Bakhtin (idem, cf., p. 74), o psiquismo individual seria a fonte de toda a língua. Por isso, “as leis da criação linguística — sendo a língua uma evolução ininterrupta, uma criação contínua — são leis da psicologia individual, e são elas que devem ser estudadas pelo linguista e pelo filósofo da linguagem” (BAKHTIN, ib).

Ora, o psiquismo é senão a própria língua manifesta em atos de fala individuais de criação linguística, sempre constantes e irrepetíveis. Isso sob a forma monológica de enunciação, ou seja, uma enunciação cuja origem supõe ser o falante - aquele que poderá controlar uma totalidade de sentidos — e não a própria relação reconhecida pelo diálogo (a ser) instituído entre um Eu, que não é cognoscível, e o outro, o interlocutor e o (seu) discurso.

Por sua vez, à segunda tendência — o objetivismo abstrato —, Bakhtin (idem, p. 85) significa-a em vista de quatro proposições assim definidas:

1. A língua é um sistema estável, imutável, de formas linguísticas submetidas a uma norma fornecida tal qual à consciência individual e peremptória para esta. 2. As leis da língua são essencialmente leis linguísticas específicas, que estabelecem ligações entre os signos linguísticos no interior de um sistema fechado. Estas leis são objetivas relativamente a toda consciência subjetiva. 3. As ligações linguísticas específicas nada têm a ver com valores ideológicos (artísticos, cognitivos ou outros) Não se encontra, na base dos fatos linguísticos, nenhum motor ideológico. Entre a palavra e seu sentido não existe vínculo natural e compreensível para a consciência, nem vínculo artístico. 4. Os atos individuais de fala constituem, do ponto de vista da língua, simples refrações ou variações fortuitas ou mesmo deformações das formas normativas. Mas são justamente estes atos individuais de fala que explicam a mudança histórica das formas da língua; enquanto tal, a mudança é, do ponto de vista do sistema, irracional e mesmo desprovida de sentido. Entre o sistema da língua e sua história não existe nem vínculo nem afinidade de motivos. Eles são estranhos entre si (ITÁLICOS DO AUTOR).

As quatro proposições resumidoras da orientação lógico-filosófica em questão são, na verdade, a antítese das quatro primeiras proposições indicadas à primeira orientação por Bakhtin. Assim, se o subjetivismo idealista reflete a realidade dos fatos linguísticos, a partir da criatividade do falante, o objetivismo abstrato, de modo oposto, encerra-os no bojo — exclusivo — do sistema da língua. Todavia, ambas orientações argumentam em direção a uma questão 
comum: prescindem a relação de dialogicidade inerente a todo uso da palavra motivado pelo falante. A segunda orientação, nesse caso, faz da língua um objeto de silêncio, (e)feito de monologismos nos quais a noção de signo — sempre ideológico para Bakhtin (1988a) — reduz-se, inadvertidamente, à ideia de mero sinal de comunicação, como um reflexo fixo das coisas no mundo.

Com efeito, nem o primado do indivíduo sobre o sistema da língua, nem o primado deste (com suas normas) sobre aquele conseguem tocar de perto a verdadeira natureza da linguagem. Isto porque nos fatos linguísticos, ao serem descritos e interpretados, urge observar o batimento (in)tensivo mantido entre o objeto língua $e$ seu funcionamento exterior. Neste passo, diríamos que a perspectiva da heterogeneidade da palavra — relida aqui pelo crivo bakhtiniano significa um modo outro de conceber a dimensão da linguagem. A esse respeito, Bakhtin (idem, p. 127) é categórico ao afirmar que:

A verdadeira substância da língua não é constituída por um sistema abstrato de formas linguísticas nem pela enunciação monológica isolada, nem pelo ato psicofisiológico de sua produção, mas pelo fenômeno social de interação verbal, realizada através da enunciação ou das enunciações. A interação verbal constitui assim a realidade fundamental da língua (ITÁLICOS DO AUTOR).

Por esse motivo, Bakhtin recusa o monologismo latente nas duas orientações do pensamento lógico-filosófico. Como a verdadeira substância da língua está na interação verbal, fundamenta o autor, a palavra que aí se (re)formula é senão heterogênea. Ela é troca entre actantes do discurso: o Eu-sujeitudinal não se limita (nem é limitado) a (por) um tu-interlocutordiscurso; ao contrário, significam-se no interstício - heterogêneo e dinâmico — impulsionado por ambos. A palavra, resumindo, não é senhora de si, posto que se ouvem e se fazem ouvir em sua matéria (dis)cursos; ela se interroga e responde, em diferentes contextos, o outro/Outro. Daí o encontro de duas ou mais palavras - eu $e$ outro(s) - corroborar, dentro do crivo bakhtiniano, o caráter heterogêneo decisivo à atividade interacional humana na linguagem.

Finalizando esta seção, vale frisar a importância da noção de heterogeneidade da palavra para os estudos linguísticos. Ora, desse prisma-outro de questões, uma linguística-outra, a da palavra em uso, emerge. Uma linguística ocupada com a compreensão daquilo que é mais singular e fundante à linguagem: o discurso e suas formas (em princípio, estáveis) de constituição. Reconhecer, a propósito, como fizeram a linguista Authier-Revuz (2004) e o 
filósofo Michel Pêcheux $(1995)^{8}$ — a questão do heterogêneo que habita a palavra é possibilidade de sustentar acirradamente a ideia de plurivocidade de linguagens, ou seja, o efeito a-mais que (se) faz sentido ao (no) discurso. Isso porque:

Na linguagem, como objeto da linguística não há e nem pode haver quaisquer relações dialógicas: estas são impossíveis entre os elementos do sistema da língua (por exemplo, entre as palavras no dicionário, entre os morfemas, etc.) ou entre os elementos do "texto" num enfoque rigorosamente linguístico deste. Elas tampouco podem existir entre as unidades de um nível nem entre as unidades de diversos níveis. Não podem existir, evidentemente, entre as unidades sintáticas, por exemplo, entre as orações vistas de uma perspectiva rigorosamente linguística. Não pode haver relações dialógicas tampouco entre textos, vistos também sob uma perspectiva puramente linguística (BAKHTIN, 2013, p. 209).

Na sequência, vejamos um pouco mais sobre a questão da heterogeneidade da palavra, contudo, dentro de uma nova visada: através da noção bakhtiniana de dialogismo. Também, esta noção serve-nos para perceber, aqui, a importância que Bakhtin confere ao estatuto da linguagem - sua dimensão efetiva - face à condição humana, face o discurso intenso e interminável de sua significação.

\section{Sobre o conceito de dialogismo}

Como ressaltado há pouco, Bakhtin (2009) pensa a língua não exatamente enquanto sistema abstrato (objetivo e homogêneo) de (suas) formas, função de um centro único subjetivopsicológico de enunciação (o do Eu), mas enquanto atividade humana, inter-ação trabalhada na e pela relação dialógica estabelecida pelo binômio Eu-outro. Disso decorre a noção de diálogo, problematizada pelo autor, de modo contundente, como condição de linguagem, sobremodo a partir do caráter ontológico que circunscreve as práticas linguísticas humanas. Assim, de acordo com o pensamento de Bakhtin (2013, p. 293), "ser significa comunicar-se pelo diálogo”.

Todavia, ao contrário do que poderíamos conjeturar, o diálogo sempre empreendido entre os protagonistas Eu-tu nunca estará restrito à ideia de comunicação verbal-vocal, face a face entre duas pessoas, formalmente. É diálogo no sentido amplo, envolvendo a língua (com

\footnotetext{
8 Esses dois estudiosos de linguagem problematizaram a questão da heterogeneidade da palavra/discurso mostrada e constitutiva —, respectivamente, pelos atravessamentos do Outro (o inconsciente), pesando-se aí o estatuto de conceitos bakhtinianos, e do Interdiscurso (um saber já-dito em outro lugar) no fio (in)tensivo de ressignificação do dizer.
} 
seu léxico, morfologia e sintaxe), os interlocutores e o contexto social, histórico e ideológico de produção de enunciados possíveis. Por isso, transcende concepção de objeto suposto tangível a sujeitos envolvidos ali. Afinal, pontua Bakhtin (1988b, p. 89), “todo discurso é orientado para a resposta e ele não pode esquivar-se à influência profunda do discurso da resposta antecipada”, já que há sempre outras falas para ele dirigidas e, ainda, a respeito dele. Em tese,

essa orientação da palavra em função do interlocutor tem uma importância muito grande. Na realidade, toda palavra comporta duas faces. Ela é determinada tanto pelo fato de que procede de alguém, como pelo fato de que se dirige para alguém. Ela constitui justamente o produto da interação do locutor e do ouvinte. Através da palavra, defino-me em relação ao outro, isto é, em última análise em relação à coletividade. A palavra é uma espécie de ponte lançada entre mim e os outros (BAKHTIN, 1988a, p. 113) (ITÁLICOS DO AUTOR).

Nessa perspectiva, a palavra — sua expressão e movimento duplamente orientados para o exterior, para a alteridade, para o discurso (do) outro - é função da dinâmica dialógica demandada pela ordem da linguagem. Seu diálogo (o da palavra) com o outro, inconcluso por natureza, implica, neste ponto, um processo (amplo e complexo) de ressignificação amiúde para o dizer; e nunca um produto interior às formas da língua ou mesmo um efeito localizável em textos por meio de marcas estruturais (travessões e os dois pontos - na escrita). Isto porque tal processo constitui-se não só de elementos linguísticos, mas também de sujeitos e de contextos sociais que têm ali seu lugar. Por razões assim, o dialogismo na/da linguagem — ou "teoria” do discurso, conforme exposta e examinada em Dostoiévski (PPD)—é, efetivamente, condição estruturante da palavra. Daí — ressalva Bakhtin (p. 293) — “o diálogo, em essência, não poder nem dever acabar”:

a todo instante se encontra nas conversas 'uma citação' ou 'uma referência' àquilo que disse uma determinada pessoa, ao que 'se diz' ou àquilo que 'todos dizem', às palavras de um interlocutor, às nossas próprias palavras anteriormente ditas, a um jornal, a um decreto, a um documento, a um livro, etc... (BAKHTIN, 1988b, p. 140).

Sinteticamente, diríamos que o conceito de dialogismo permite seu autor (Bakhtin) construir uma teoria linguístico-filosófica da linguagem; ela reavalia, fundamenta e assume de vez o modo de tessitura do discurso como heterogêneo. Sem delongas, observa-se, pois, que “toda a vida da linguagem, seja qual for o seu campo de emprego (a linguagem cotidiana, a 
prática, a científica, artística, etc.), está impregnada de relações dialógicas” (BAKHTIN, 2013, p. 209).

Assim sendo, toda relação dialógica é potencialmente questionadora da ideia de monologismo, isto é, a força centrípeta e inibidora da palavra do outro, do estabelecimento de consciências conjuntas, da palavra que espera ser escutada pelo Eu sujeito de/do discurso. Essas (as relações dialógicas), com efeito, podem fazer com que emirja, discursivamente, algo daquilo que Bakhtin (2009) concebe por arquitetônica (ético-estética) da palavra: a relação valorativa das posições-sujeito “eu-para-mim”, “eu para o outro” e “outro para mim”. Esses valores denotam, em essência, a condição de duplicidade inerente à noção de dialogismo bakhtiniana. A antecipação compreensiva da resposta (a ser) dada pelo outro da interlocução e a relação Eu e outro que fala no sujeito (o superdestinatário) são demonstrações cabíveis a (e)feitos prováveis de serem produzidos na/pela linguagem.

Ademais, cumpre sublinhar que o conceito de dialogismo abarca, entre outras questões não necessariamente linguísticas — por exemplo, a vida humana, o diálogo motivado por gestos de interrogar, ouvir, responder o dizer —, a compreensão da noção de enunciado formulada por Bakhtin em "Estética da criação verbal” (1997). Ali, o autor, refletindo sobre o dinamismo de funcionamento da linguagem, pelo crivo dialógico, lembra-nos de que esta sempre se articula entre relações de enunciados, isto é, unidades de comunicação (irrepetíveis) produtoras de enunciações conclusas imaginariamente (BAKHTIN, idem, cf., p. 299). Tais unidades, os enunciados, são, por assim dizer, realidades constituídas historicamente, respondendo, nesse caso, um outro, o outro que constitui e institui a subjetividade do Eu. Por isso, todo enunciado significa, na óptica do filósofo Bakhtin (idem), o elemento fundante e, ao mesmo tempo, propulsor às relações dialógicas na linguagem. Consequentemente, poder-se-á afirmar que

(...) na composição de quase todo enunciado do homem social — desde a curta réplica do diálogo familiar até as grandes obras verbal-ideológicas (literárias e outras) existe, numa forma aberta ou velada, uma parte considerável de palavras significativas de outrem, transmitidas por um ou outro processo. No campo de quase todo enunciado ocorre uma interação tensa e um conflito entre sua palavra e a de outrem, um processo de delimitação ou de esclarecimento dialógico mútuo (...) (BAKHTIN, 1988b, p. 153). 
Feitas essas primeiras observações sobre a noção de dialogismo, volvemo-nos, agora, a outro conceito crucial às teses de Bakhtin: o conceito de polifonia ${ }^{9}$. Antes, cabe pontuar o seguinte esclarecimento: a teoria polifônica bakhtiniana não subsome a perspectiva dialógica na/da linguagem relida, em linhas gerais, aqui. Trata-se de uma nova elaboração teórica do autor que, a despeito de constituir-se dentro de um quadro de questões dialógicas, distancia-se (e muito) daí; vai além da ideia de diálogo entre interlocutores e de plurivocalidade da palavra. Dialogismo, dito de outro modo, é uma propriedade determinante - relação necessária entre valores heterogêneos — da (na) linguagem. Polifonia, diferentemente, é uma realidade dialógica de linguagem notada e perscrutada por Bakhtin a partir do trabalho artístico-literário do escritor russo Fiódor Mikhailovich Dostoiévski (1821-1881), inventor do gênero romance polifônico.

Sendo assim, para início de discussão, recordamos que o conceito de polifonia — uma metáfora formulada no contexto da música ${ }^{10}$, a priori - decorre de problematizações engendradas por Bakhtin (2013) ao (re)pensar e, em seguida, fundamentar os tópicos heterogeneidade e dialogismo da palavra em um (con)texto específico: o discurso romanesco e sua inovação no campo literário impulsionada por Dostoiévski. Significa, noutras palavras, um conceito voltado para a compreensão do estatuto do outro na composição do dizer — com semelhanças devidas às de um sistema musical não-monódico: uso de linguagem dinâmica $e$ mutável, flutuante $e$ ativa, múltipla $e$ ambígua. Enfim, uma linguagem em processo vivo e criativo, função de variados ritmos sociais que compõem, ininterruptamente, diálogos entre si. Com efeito, a palavra (ex)posta em obras de Dostoiévski — sua confluência e congruência até outras palavras, consciências e tons — é um verdadeiro diálogo interminável.

\footnotetext{
${ }^{9}$ Embora não seja foco deste estudo demonstrar operacionalizações do conceito de polifonia na/da linguagem, cumpre ressaltar a importância do trabalho de Ducrot (1984), ocupado de tal empreitada. Neste ponto, é sabido que o autor esboçou, sob a perspectiva teórica da Semântica da Enunciação, um novo quadro de questões essencialmente linguísticas — favoráveis à ideia de se localizar, no fio do dizer, vozes constitutivas de discursos. Para tanto, pôs-se, inicialmente, a observar a linguagem a partir de dois planos, a saber, pelo plano do locutor (o de quem fala) e pelo plano do enunciador (o de quem vê). Ali, em tese, na relação instituída entre (inter)locutores, é que se encontra o fundamento de sua teoria polifônica, a presença flagrante de vozes diferentes que não podem ser atribuídas a um sujeito psicológico, uno, senhor de si — conclui Ducrot (idem). Algo muito diferente daquilo que postulam as lucubrações do filósofo russo Bakhtin em PPD.

${ }^{10}$ Esse esclarecimento deve ser remetido a Roman (1992). O autor, propondo uma releitura e compreensão do trajeto de elaboração da metáfora polifonia em Bakhtin, lembra-nos de que tal proposição re(a)presenta e confronta ao canto gregoriano/monódico (no séc. XIII) um modo outro de compor e de tocar melodias: o estilo polifônico. Este, sob forma de linguagem dinâmica e irrepetível, é, na verdade, uma (re)elaboração bakhtiniana que, legitimando o princípio (heterogêneo) de não acabamento e de não perfeição do discurso, confere estatuto à ideia segundo a qual pode haver consciências humanas múltiplas escutando-se dialogicamente, sem que uma dessas (sobre)determine e apague outras.
} 
Acolhe e se faz acolhida pela alteridade, significando-se, ali, não como objeto de controle de um autor, mas, em mesmo pé de igualdade, como sujeito que também cala para escutar o Eu que (se) diz, (d)enuncia (o) outro. Em tese, esse é o cerne da teoria polifônica bakhtiniana, da ideia de interação (des)envolvida a partir de várias consciências imiscíveis em um mesmo texto/discurso. Assim, no entendimento de Bakhtin (2013, p. 5):

A multiplicidade de vozes e consciências independentes $e$ imiscíveis e a autêntica polifonia de vozes plenivalentes constituem, de fato, a peculiaridade fundamental dos romances de Dostoiévski. Não é multiplicidade de caracteres e destinos que, em um mundo objetivo uno, à luz da consciência de um autor, se desenvolve nos seus romances; é precisamente a multiplicidade de consciências equipolentes e seus mundos que aqui se combinam numa unidade de acontecimento, mantendo a sua imiscibilidade (ITÁLICOS DO AUTOR).

Esta citação, que pontua em rigor questões constitutivas do conceito de polifonia compreendido por Bakhtin a partir do discurso dostoiévskiano - em particular, a partir da ideia de multiplicidade substancial de consciências equipolentes e da de vozes plenivalentes serve-nos, no momento, para enfatizar peculiaridades dialógicas na/da linguagem literária. Neste ponto, reiteradas as palavras do autor (p. 4-5), em PPD, notar-se-ão as explicações seguintes (em notas de rodapé): $1^{\text {a }}$ ) Multiplicidade de consciências equipolentes = “consciências e vozes que participam do diálogo com outras vozes em pé de absoluta igualdade; não se objetificam, isto é, não perdem o seu SER como vozes e consciências autônomas; $2^{\mathrm{a}}$ ) polifonia de vozes plenivalentes = vozes "plenas de valor, que mantêm com outras vozes do discurso uma relação de absoluta igualdade como participantes do grande diálogo”.

Ora, como se vê, há um fundamento singular implicando o processo dialógico polifônico perscrutado por Bakhtin na criação artística do escritor russo Dostoiévski, qual seja, a noção de interação entre vozes/consciências construídas discursivamente. Estas, na óptica do autor, sempre falam, escutam-se, interagem-se, em um mesmo espaço — havendo aí, no mínimo, duas vozes em jogo (a do autor que fala com sua personagem e a da própria personagem que questiona a posição-autor) —, e não simplesmente simulam esperada multiplicidade vocal; a multiplicidade que, configurada na forma monológica de diálogo, tende, em função de certo pensamento único/autoritário, a sufocar consciências, neutralizar vozes. A esse respeito, são esclarecedoras as afirmações seguintes do autor: 
Dostoiévski é o criador do romance polifônico. Criou um gênero romanesco essencialmente novo. Por isso sua obra não cabe em nenhum limite, não se subordina a nenhum dos esquemas histórico-literários que costumamos aplicar às manifestações do romance europeu. Suas obras marcam o surgimento de um herói cuja voz se estrutura do mesmo modo como se estrutura a voz do próprio autor no romance comum. A voz do herói sobre si mesmo e o mundo é tão plena como a palavra comum do autor; não está subordinada à imagem objetificada do herói como uma de suas características, mas tampouco serve de intérprete da voz do autor. Ela possui independência excepcional na estrutura da obra, é como se soasse ao lado da palavra do autor, coadunando-se de modo especial com ela e com as vozes plenivalentes de outros heróis (BAKHTIN, idem, p. 5) (ITÁLICOS DO AUTOR).

Uma vez mais, notamos aqui especificidades do estatuto da noção de polifonia dentro arcabouço teórico bakhtiniano. A citação em tela, nesse passo, sublinha bem três princípios de sua constituição: a equipolência, a plenivalência e a imiscuidade de vozes/consciências no/do discurso. No que toca os três princípios, diríamos, então, que são ingredientes singulares à escrita de Dostoiéviski, o cerne caracterizador de todo um procedimento discursivo polifônico - que, pautado no diálogo aberto entre consciências múltiplas, constrói um todo, um ideal de linguagem (romanesca). $\mathrm{O}$ ato de fazer personagens e autor dialogarem entre si e com o outro do discurso, tornando-os plenos de direitos iguais, é, por conseguinte, peculiaridade do estilo dostoiéviskiano. Por isso, ali, a ideia de polifonia significando "múltiplas vozes/consciências do/no discurso" torna-se um gesto redutor e insuficiente perante a questões ético-estéticas descritas por Bakhtin. Na literatura de Dostoiéviski, em suma, há que ser notado o diálogo inconcluso de personagens; estes como sendo livres e podendo até mesmo discordar de seu criador (BAKHTIN, cf., p. 4). Nada, de certa forma, subordinado ao crivo individual de um autor.

Veja-se, mediante as observações precedentes, que o estatuto atribuído ao outro como estruturante do Eu na linguagem dostoiéviskiana é patente às lucubrações de Bakhtin revisitadas aqui. Ora, a despeito de haver diferenças — extensões - fundantes aos conceitos de heterogeneidade da palavra, de dialogismo e de polifonia nos textos do autor, mesmo assim, o princípio unificador de toda sua empreitada teórica em questão é a relação Eu-outro, o diálogo interior $e$ exterior à palavra; sendo este um efeito subsumido e trabalhado (sempre) pelo falante de língua. Sobre tal princípio, sabe-se que Bakhtin volve-se a ele, sob perspectiva filosófica uma metalinguística - para tratar dialeticamente da relação palavra-palavra, pe(n)sando, para tanto, o ideal de complementariedade entre interlocutores no fio do discurso. Neste, a não indiferença à palavra-outra, interior e anterior ao Eu (a confluência de consciências com foco 
na construção de um “mesmo” objeto de discurso), é justamente aquilo que define a ideia de uma exotopia $^{11}$ na/da linguagem literária, posto que se assume aí, radicalmente, a alteridade; realidade essa que recoloca o discurso em um processo continuum de ressignificação e de movimentos intersubjetivos de escuta do outro.

A seguir, propomos uma releitura da noção de exotopia, outra formulação que, em Bakhtin (1997), problematiza fatos de polifonia discursiva na linguagem (literária). Trata-se, resguardadas suas especificidades, de outro conceito do autor, ocupado - mais ainda - em fundamentar e demonstrar a ideia de dialogismo circunscrita à linguagem humana. Grosso modo, uma "polifonia” flagrada no discurso (in)tensivo de (re)criação literária, na produção ético-estética da palavra.

\section{Sobre o conceito de exotopia}

Outra questão importante, também interligada à perspectiva dialógica bakhtiniana, é a ideia de excedente de visão — ou exotopia — que a relação Eu-outro pode suscitar à palavra. Para formulá-la, Bakhtin, in "Estética da criação verbal” (1997), interessado em saber mais sobre o binômio autor-personagem/herói ${ }^{12}$ (sua trama vocal), coloca em discussão o princípio segundo o qual o outro é o meio (e não o fim) de (re)avaliação de dizeres do Eu. Noutras palavras, espera-se que o Eu vá ao encontro do outro de sorte a compreender fatos, realidades e acontecimentos ocorridos - também, pelo crivo de sua visão, a qual é única — e permitirse, em contrapartida, (re)ver-se em formas-outras de se relacionar com o mundo. Com isso, o Eu amplia e fundamenta pontos de vista antes indefinidos para si. Na prática, avalia Bakhtin (idem, p. 23):

eu devo entrar em empatia com esse outro indivíduo, ver axiologicamente o mundo de dentro dele tal qual ele vê, colocar-me no lugar dele e, depois de ter retornado ao meu lugar, contemplar o horizonte dele com o excedente de visão que desse lugar se descortina fora dele.

Sendo assim, o princípio de exotopia na linguagem implica, concomitantemente, dois mo(vi)mentos importantes à sua realização: distanciamento $e$ proximidade entre o Eu e o outro. Nesse passo, supõe-se uma “permuta” necessária às posições Eu-outro, já que em qualquer

\footnotetext{
${ }^{11}$ A interação Eu-outro autoriza-lhes o retorno a si, dentro de um horizonte de visão do outro. O efeito disso, a exotopia, dá ao Eu a possibilidade de notar o mundo de um lugar-outro: na/pela fronteira Eu-outro.

${ }^{12}$ Faraco (1988) nos faz lembrar que a palavra literária assume melhor o outro, a alteridade, a relação instituída com ela mesma. Neste ponto, cumpre dizer que, em Bakhtin, o exame do conceito de exotopia faz coro com prerrogativa assim.
} 
discurso pode ocorrer abafamento da posição vocal do Eu ante o outro; fato que acaba reproduzindo este, de maneira irrefletida, na forma monológica. A esse respeito, Bakhtin (1997, p. 21) lembra-nos, ainda, de que:

em qualquer situação ou proximidade que esse outro que contemplo possa estar em relação a mim, sempre verei e saberei algo que ele, da sua posição fora e diante de mim, não pode ver [...] toda uma série de objetos e relações que, em função dessa ou daquela relação de reciprocidade entre nós, são acessíveis a mim e inacessíveis a ele.

$\mathrm{O}$ ato de ir ao outro e, em seguida, voltar a si constitui-se, por conseguinte, contraparte do processo dialógico. Nesta feita, a visão exotópica processada aí, pelo gesto de empatia do Eu com outro, traz um ponto de vista novo para cada uma dessas posições discursivas; ver o mundo (também) com a lente do outro é o fulcro de tal ato-processo. O Eu, na presença do outro, não é mais singular; é um Eu plural (Eu + outro). Nem o outro é outro nele mesmo, senhor de si, de uma verdade suposta, mas outro do Eu. Isso tudo, em resumo, se dá por um motivo único: o Eu e o outro, instâncias discursivas de significação, assumem para si um trabalho de compreensão responsiva $e$ ativa da palavra (BAKHTIN, 1988). "Eu me identifico ativamente com uma individualidade e, consequentemente, eu não me perco completamente, nem perco meu lugar único de fora dela, sequer por um momento”, pondera Bakhtin (1997, p. 33).

Com efeito, ao Eu — indo ao encontro do outro, identificando-se com ele (mesmo que parcialmente) - cabe atenção para não se perder nesse ato volitivo-interativo, porque, do contrário, passará a ser outro (fusão), e não um complemento de si mesmo, uma nova perspectiva, possibilidade de acabamento do (seu) dizer a partir de elementos que lhe são exteriores. Assim, o Eu deverá posicionar-se ante o ponto de vista do outro, trabalhando-o e trabalhando a si mesmo, numa relação dialógica produtiva. O efeito disso encontra-se no ato ético de o Eu, na relação assumida com o outro, gerar uma consciência-outra, significar-se, pois, não mais de modo igual ao de antes (BAKHTIN, 1997).

Tudo isso, sem delongas, implica a gestação de uma palavra-outra, a que é produzida na/pela presença da alteridade. Uma palavra que não seja ela própria — dona de si centralizada nem no Eu, unicamente, nem perdida no outro. Mas uma palavra acolhedora do outro, um (e)feito de escuta (embate) de discursos-outros. Não se marca, nesse caso, na e pela palavra-outra, uma oposição. Ora, esta, a propósito, poderia ser construída por meio de raciocínios lógicos, com foco na ideia suposta mal entendida, ou seja, por elementos que dentro 
do esquema aristotélico “tese + antítese = síntese” são postos em confronto, para, em seguida, eliminar um ou mais pensamentos previstos para dado tema - raciocínio que não convém à palavra-outra, posto que pode ser, ao contrário do imaginado, igual ao outro na sua diferença.

Demais, a relação dialógica Eu-outro — enfatizada aqui pela produtividade exotópica suscetível à linguagem — não pode ser compreendida, em realidade alguma, como resposta a um ato sujeitudinal exterior a certo processo de significação. Diferentemente, envolve um olhar nosso para a posição assumida pelo Eu ante a outra palavra, a qual se (re) constrói (sempre) como irrepetível, plena de valores. Ali está implicado uma questão de ato responsável, pondera Bakhtin (2009). O “ato da palavra viva”, da palavra que não prescinde o outro, a que, sem afirmar uma plenivalência para o Eu ou mesmo fundir-se à ideia ${ }^{13}$ da posição-autor, (des)envolve-se harmonicamente na ordem heterogênea da linguagem.

Enfim, antes de passar à análise, frisamos que os textos bakhtinianos relidos aqui conferem estatuto singular ao outro em processos de instituição da palavra, o seu diálogo interior $e$ exterior. Neste ponto, sabemos que, no âmbito dos estudos linguísticos, não mais é novidade a afirmação “todo discurso é feito de relações dialógicas”. Todavia, o cuidado com extensões teórico-metodológicas engendradas daí - por exemplo, o conceito de polifonia, conforme aludido e (re)examinado na seção anterior — se faz sempre necessário a todo estudioso de linguagem. Afinal, certos fetichismos teóricos não podem (e não devem) vencer o olhar investigador, aquele a quem, mediante suspeitas constantes com o saber, cumpre sempre ouvir o outro — verdadeiro - fundante do Eu.

\section{5. (Per)curso e mo(vi)mento de análise}

Mediante as releituras do arcabouço teórico bakhtiniano (re)construídas nas seções precedentes, estabelecemos, agora, de modo mais preciso, uma possibilidade de discussão acerca da presença do outro - seu estatuto e caracterização prováveis (polifonia ou sobreposição de discursos?) — em um (con)texto particular: a redação ENEM (2011); orientando-nos, nesse passo, pelo batimento (in)tenso e necessário entre teoria $e$ prática.

\footnotetext{
${ }^{13}$ Em PPD, Bakhtin enfatiza bastante o aspecto dialógico da linguagem. Para tal, utiliza-se de extensões teóricometodológicas de sorte a (re)afirmar fatos que ganham consistência/sentido aí. Tem-se, a propósito, conforme desenvolvida pelo autor, no conceito de "ideia”, um outro fundamento implicado à palavra. Aqui, grosso modo, lembramos que esta (a ideia), nunca pronta, precisa ser notada como sendo coletiva — jamais a de um indivíduo —, já que é “acontecimento vivo” de linguagem: interroga-se no/pelo outro e, por isso, quer ser ouvida, respondia por outras ideias, outros enunciados (BAKHTIN, p. 94-95).
} 
Resumindo, diríamos que o presente mo(vi)mento analítico vem corroborar afirmações feitas por nós — com base em estudos de Bakhtin (1988a e 1988b; 1997; 2013 [1981]) — em torno da matéria linguagem e sua realidade fundamentalmente dialógica. A relação scriptor $^{14}$ e enunciados constitui, doravante, o cerne de nossas compreensões.

No tocante ao material selecionado para análise, uma das seis redações "Nota 1000”15 que compuseram o "Guia do Participante ENEM ” (BRASIL, 2012), cumpre dizer que há ali mo(vi)mentos argumentativos construídos por um scriptor que muito nos interessam. Esses mo(vi)mentos produzem-se a partir de informações fornecidas pela instância avaliativa ENEM (2011) ao vestibulando e instituem-se, concomitantemente, a partir de categorias argumentativas tais como já ditos (consensos), contra-argumentos e paráfrases. Antes de examiná-las aqui, atentemo-nos à leitura da redação abaixo (R1):

\section{R1: Redes sociais: o uso exige cautela}

Uma característica inerente às sociedades humanas é sempre buscar novas maneiras de se comunicar: cartas, telegramas e telefonemas são apenas alguns dos vários exemplos de meios comunicativos que o homem desenvolveu com base nessa perspectiva. E, atualmente, o mais recente e talvez o mais fascinante desses meios, são as redes virtuais, consagradas pelo uso, que se tornam cada vez mais comuns. Orkut, Twiter e Facebook são alguns exemplos das redes sociais (virtuais) mais acessadas do mundo e, convenhamos, a popularidade das mesmas se tornou tamanha que não ter uma página nessas redes é praticamente como não estar integrado ao atual mundo globalizado. Através desse novo meio as pessoas fazem amizades pelo mundo inteiro, compartilham ideias e opiniões, organizam movimentos, como os que derrubaram governos autoritários no mundo árabe e, literalmente, se mostram para a sociedade. Nesse momento é que nos convém cautela e reflexão para saber até que ponto se expor nas redes sociais representa uma vantagem.

Não saber os limites da nossa exposição nas redes virtuais pode nos custar caro e colocar em risco a integridade da nossa imagem perante a sociedade. Afinal, a partir do momento em que colocamos informações na rede, foge do nosso controle a

\footnotetext{
${ }^{14}$ Conceito elaborado por Calil (2008). Refere-se à possibilidade de um sujeito de linguagem ocupar, ao mesmo tempo, a posição de leitor e escrevente de textos.

15 Esse rótulo caracteriza, explica “Guia Participante - ENEM” (BRASIL, 2012, p.31), as “(...) redações que receberam pontuação máxima — 1000 pontos — no Enem 2011”, por terem cumprido todas as 5 competências prescritas ali (“Competência n.1: Demonstrar domínio da norma padrão da língua escrita”; “Competência n.2: Compreender a proposta de redação e aplicar conceitos das várias áreas de conhecimento, para desenvolver o tema dentro dos limites estruturais do texto dissertativo-argumentativo”; "Competência n.3: Selecionar, relacionar, organizar e interpretar informações, fatos, opiniões e argumentos em defesa de um ponto de vista”; “Competência n. 4: Demonstrar conhecimento dos mecanismos linguísticos necessários para a construção da argumentação”; "Competência n. 5: Elaborar proposta de intervenção para o problema abordado, respeitando os direitos humanos”).
} 
consciência das dimensões de até onde elas podem chegar. Sendo assim, apresentar informações pessoais em tais redes pode nos tornar um tanto quanto vulneráveis moralmente.

Percebemos, portanto, que o novo fenômeno das redes sociais se revela como uma eficiente e inovadora ferramenta de comunicação da sociedade, mas que traz seus riscos e revela sua faceta perversa àqueles que não bem distinguem os limites entre as esferas públicas e privadas “jogando” na rede informações que podem prejudicar sua própria reputação e se tornar objeto para denegrir a imagem de outros, o que, sem dúvidas, é um grande problema.

Dado isso, é essencial que nessa nova era do mundo virtual, os usuários da rede tenham plena consciência de que tornar pública determinadas informações requer cuidado e, acima de tudo, bom senso, para que nem a própria imagem, nem a do próximo possa ser prejudicada. Isso poderia ser feito pelos próprios governos de cada país, e pelas próprias comunidades virtuais através das redes sociais, afinal, se essas revelaram sua eficiência e sucesso como objeto da comunicação, serão, certamente, o melhor meio para alertar os usuários a respeito dos riscos de seu uso e os cuidados necessários para tal.

Produzida a leitura da R1, propomos um primeiro gesto de análise para a categoria de já-ditos presente ali. Neste ponto, realizado o cotejo de informações expostas nos $\mathrm{TMs}^{16} \mathrm{com}$ a redação em tela, pudemos notar que seu scriptor recupera o outro do senso comum (sua voz) — a propósito, no título da R1 — de sorte a redizer, pelo diálogo, a seguinte opinião escutada no TM2: "Um dos maiores desafios dos usuários de internet é saber ponderar o que se publica nela”. Ora, sem delongas, vê-se aí o uso comum de uma afirmação constitutiva de discursos pedagógicos; nesse, conforme sabemos, enunciam-se coisas que, moralmente, não devem ou deveriam ser feitas por nós ao escrever textos. Fato que é recuperado, de saída, pela palavra do scriptor, que se alinha a tal pensamento em defesa de uma tese.

Com efeito, o gesto-scriptor, que retoma palavras construídas socialmente, configurase, no plano da argumentação, como um caso de monofonismo. Ou seja, existe aí um discurso já-dito (formalizado e reconhecido) sobre o mau uso das redes sociais (Orkut, Twiter e Facebook) por usuários — “A internet é um meio público no qual não devemos falar tudo de nós para todos, abertamente”, pronuncia o discurso social — impondo-se à escrita da R1, sem ser questionado. Isso, em decorrência, expurga a exotopia, relação Eu-outro (a função autor) passível a (em) fatos de linguagem, dado que um discurso outro deixa de emergir ali, pelo lado de fora. Na R1, então, o scriptor, fazendo uso de tal discurso, recupera um ponto de vista aceito em nossa sociedade - um já-dito também dito no TM2 - e absolutiza-o. Com isso, não se

\footnotetext{
16 Textos motivadores (TM1, 2 e 3) (Cf., Anexo 1).
} 
busca um contexto-outro, que poderia produzir novo efeito de conclusibilidade imaginária para enunciados dos TMs.

Seguindo este (per)curso de análise, outras observações podem ser feitas aqui; agora, para o uso do recurso contra-argumentação mediante o qual, também, o scriptor da R1 dialogou para produzir a R1. Esse recurso, uma injunção da instância ENEM à redação do vestibulando (BRASIL, 2012, p.7), é, na verdade, uma demanda que responde ao esquema formal-textual [tema $\rightarrow$ tese + argumentos (antítese) $=$ síntese]. No caso, vê-se que, na redação exibida, a reformulação de enunciados do TM2 (onde são sublinhadas realidades de uso da rede internet) foi agenciada por seu scriptor (certamente) como forma de dialogar com a proposta redacional ENEM. Ou seja, ele vai ao encontro da palavra do outro, que nos informa acerca de aspectos positivos das redes sociais, para extrair daí pontos favoráveis à sua argumentação. Assim, flagramos na R1, uma vez mais, a determinação do discurso motivador (TMs) sobre o dizer do scriptor. Ali, assiste-se, pois, um direcionamento (pelo formato textual dissertativoargumentativo) de uma voz única: o da voz que, em meio a outras, (re)luta para ser reafirmada.

Ademais, no tocante à categoria argumentativa utilizada pelo scriptor na R1 - a paráfrase de enunciados dos TM2 - consideramos que seus efeitos não muito se distanciam da de já-ditos e contra-argumentação. Na R1, em vários espaços, verifica-se que o scriptor confrontou os discursos dos TMs - o primeiro deles (re)diz sobre o sucesso da internet mundialmente, o segundo sobre a cautela que devemos ter ante o uso de redes sociais e o terceiro, em tom crítico, sobre a contradição dessa realidade: em ambiente de rede, monitoramos a vida alheia, mas também somos monitorados pelo outro — via paráfrases, satisfazendo, com efeito, uma ordem externa (a da banca de correção de redações ENEM). Porém, tal gesto (o ato de confrontar discursos) não se abre para emergência de um discurso-outro questionador da voz enunciada na coletânea de TMs. Em tese, cria-se, com isso, uma unilateralidade de pensamento; ora, na R1, inexistem enunciados que se reúnem para discutir posições - por que não? contrárias acerca do tema "Viver em rede no século XXI" (conforme se efetiva em atividades dialéticas produtivas).

Enfim, às três categorias argumentativas examinadas aqui pela escrita da R1 indicamos um traço comum: todas elas trabalham no sentido de homofonizar/plasmar o discurso que poderia dialogar harmonicamente com palavras (vozes) outras - discurso esse que barraria a institucionalização de dizeres, a ação banal à produção de escritas no ENEM, na qual se veem scriptors reproduzindo posicionamentos improfícuos ao tomar partido por uma e outra 
realidade já discursivisadas socialmente. Aqui, uma ponderação cabe ser feita: nossa análise não pressupõe uma questão valorativa à escrita da R1. Esta (R1), melhor dizer, institui-se mediante um discurso particular: o monofônico. E não mediante a adensamento de vozes (polifonias), consoante constatou Bakhtin (2013), por exemplo, em PPD.

\section{Palavras (in)conclusivas: algumas ponderações}

Vê-se, por conseguinte, que a redação analisada, apesar de atenta a injunções (externas) da palavra do outro, é monofônica. Ora, os recursos argumentativos que instituem seu (dis)curso, salientados em nossa análise, consolidam, de fato, a existência de pensamentos construídos ali por sobreposição discursiva (pelo discurso da instância avaliativa ENEM). Como não encontramos multiplicidade vocal na produção escrita do scriptor (R1) plenivalência e equipolência de vozes — , não podemos enquadrá-la na categoria polifônica, conforme compreendida por Bakhtin (2013). Neste ponto, a argumentação do scriptor (na R1) é dialógica, em partes, - dialoga com os TMs da prova de redação-ENEM e efetiva, com isso, um embate (já-dito) de posições acerca de um tema —, mas não polifônica, isto é, com menção à voz do outro, conjuntamente, sem neutralizá-la.

Por esse motivo, a ponderação seguinte, do estudioso de linguagem Faraco (2008), mostra-se pertinente a toda a discussão (pro)movida por nós no (com o) presente estudo. De acordo com o pensamento do autor (idem, p. 49), nota-se, então, que “o termo polifonia vale hoje mais pela sedução derivada de livres associações do que como categoria coerente de um certo arcabouço teórico”. Isto ocorre porque a categoria polifônica bakhtiniana (sua natureza) é inacabada conceitualmente (FARACO, cf. ib.). Caso Bakhtin — em PPD (2013) - tivesse enfatizado os procedimentos teórico-metodológicos de uso desse conceito, aí, sim, estariam mais bem (res)guardadas especificidades que o constituem. Em suma, as vulgatas, hoje (ainda) em circulação, existiriam em menor realidade, desfazendo-se, pois, da indiferença neutralizadora do outro, a alteridade constitutiva da palavra. A escuta epistemológica, em todo caso, será sempre cara e necessária à pesquisa científica.

\section{Referências}

AUTHIER, R., J.. Entre a transparência e a opacidade: um estudo enunciativo do sentido; apresentação Marlene Teixeira; revisão técnica da tradução: Leci Borges Barbisan e Valdir do Nascimento Flores. — Porto Alegre: EDIPUCRS, 2004. 
BAKHTIN, M. Marxismo e filosofia da linguagem. São Paulo: Hucitec, 1988a.

Questões de literatura e estética: a teoria do romance. São Paulo: Hucitec, 1988b.

. Estética da criação verbal. São Paulo: Martins Fontes, 1997.

. Para uma filosofia do ato: válido e inserido no contexto. In: BRAIT, B. Bakhtin: dialogismo e polifonia. São Paulo: Contexto, 2009. p. 17-43.

Problemas da poética de Dostoievski. Rio de Janeiro: Forense Universitária, 2013. BENVENISTE, É. Problèmes de linguistique générale I. Paris: Gallimard, 1966.

Problèmes de linguistique générale II. Paris: Gallimard, 1974.

BRASIL. Ministério da Educação. Instituto Nacional de Estudos e Pesquisas Educacionais Anísio Teixeira (Inep). Diretoria de Avaliação da Educação Básica (DAEB). A Redação no ENEM 2011. Guia do Participante. Brasília-DF, 2012. 45p. Disponível em: < http://download. inep.gov.br/educacao_basica/Enem/guia >. Acesso em: 26.06.2014.

CALIL, E. Escutar o invisível: escritura e poesia na sala de aula. Rio de Janeiro: FUNARTE, 2008.

DUCROT, O. O dizer e o dito. Campinas, São Paulo: Pontes, 1984.

FARACO, C. A. A invasão silenciosa e a má-leitura. In: Curitiba, Hatier, 1988, p. 19-36. . Uma introdução a Bakhtin.

Autor e autoria. In: BRAIT, Beth (Org.). Bakhtin: conceitos-chave. São Paulo: Contexto, 2008.

PÊCHEUX, M. Semântica e discurso: uma crítica à afirmação do óbvio. Campinas: Editora da UNICAMP, 1988.

ROMAN, A. R. O conceito de polifonia em Bakhtin - O trajeto polifônico de uma metáfora. Letras, Curitiba, n. 4, p. 207-220, novembro, 1992.

\section{ANEXO (1):}

Com base na leitura dos textos motivadores seguintes e nos conhecimentos construídos ao longo de sua formação, redija texto dissertativo-argumentativo em norma padrão da língua portuguesa sobre o tema VIVER EM REDE NO SÉCULO XXI: OS LIMITES ENTRE O PÚBLICO E O PRIVADO, apresentando proposta de conscientização social que respeite os direitos humanos. Selecione, organize e relacione, de forma coerente e coesa, argumentos e fatos para defesa de seu ponto de vista.

TM1 - Liberdade Sem Fio 
A ONU acaba de declarar o acesso à rede um direito fundamental do ser humano - assim como saúde, moradia e educação. No mundo todo, pessoas começam a abrir seus sinais privados de wi-fi, organizações e governos se mobilizam para expandir a rede para espaços públicos e regiões onde ela ainda não chega, com acesso livre e gratuito.

ROSA, G.; SANTOS, P. Galileu. No 240, jul. 2011 (fragmento).

\section{TM2 - A internet tem ouvidos e memória}

Uma pesquisa da consultoria Forrester Research revela que, nos Estados Unidos, a população já passou mais tempo conectada à internet do que em frente à televisão. Os hábitos estão mudando. No Brasil, as pessoas já gastam cerca de $20 \%$ de seu tempo on-line em redes sociais. A grande maioria dos internautas (72\%, de acordo com o Ibope Mídia) pretende criar, acessar e manter um perfil em rede. "Faz parte da própria socialização do indivíduo do século XXI estar numa rede social. Não estar equivale a não ter uma identidade ou um número de telefone no passado”, acredita Alessandro Barbosa Lima, CEO da e.Life, empresa de monitoração e análise de mídias.

As redes sociais são ótimas para dissemiar ideias, tornar alguém popular e também arruinar reputações. Um dos maiores desafios dos usuários de internet é saber ponderar o que se publica nela. Especialistas recomendam que não se deve publicar o que não se fala em público, pois a internet é um ambiente social e, ao contrário do que se pensa, a rede não acoberta anonimato, uma vez que mesmo quem se esconde atrás de um pseudônimo pode ser rastreado e identificado. Aqueles que, por impulso, se exaltam e cometem gafes podem pagar caro.

Disponível em: http://www.terra.com.br. Acesso em: 30 jun. 2011 (adaptado).

TM3 -

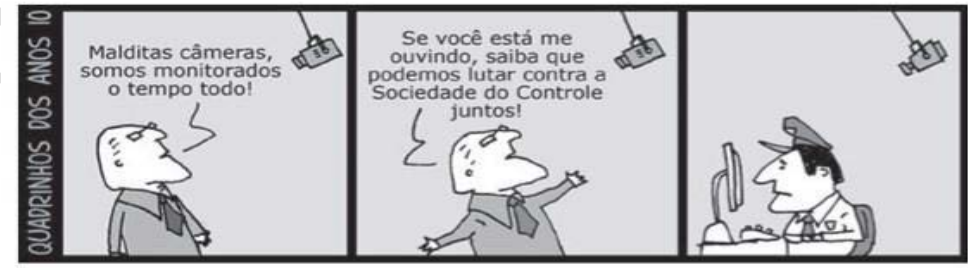

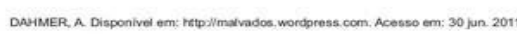

Artigo recebido em: 03.01.2015

Artigo aprovado em: 15.01.2015 